\title{
Laudatio for Dr. Richard M. Lindstrom
}

\author{
Sam Glover
}

Received: 28 July 2009/Published online: 23 August 2009

(c) Akadémiai Kiadó, Budapest, Hungary 2009

Dr. Richard M. Lindstrom was born in Ashland, Wisconsin, USA. He received his B.S. (Honors) from the University of Wisconsin, Madison, in 1963, and Ph.D. in 1970 from the University of California, San Diego. His Ph.D. dissertation "Radionuclides in Meteorites and in the Lunar Surface" was one of the first theses to be based on the Apollo 11 lunar samples. He then went to the Tata Institute of Fundamental Research in Bombay as a postdoctoral fellow, and a year later moved to Brookhaven National Laboratory. Dr. Lindstrom joined the National Bureau of Standards (NBS, now NIST) in 1972 to develop a lowbackground counting laboratory. In 1974 he moved to the Inorganic Chemical Metrology Group, concentrating on accurate methods of elemental analysis using a variety of nuclear techniques.

Dr. Lindstrom pioneered the development of promptgamma activation analysis (PGAA) and its application to the elemental characterization of substances and certification of Standard Reference Materials (SRMs). He also led a team of specialists to develop the world's first cold-neutron PGAA system at NIST, and participated in establishing PGAA facilities in Japan and Hungary. With other scientists, Dr. Lindstrom used PGAA to detect neutron standing waves for the first time, and also measured the 200microbarn thermal neutron cross section of ${ }^{208} \mathrm{~Pb}$, with implications for nucleosynthesis and nuclear models.

\footnotetext{
S. Glover $(\bowtie)$

University of Cincinnati, Cincinnati, USA

e-mail: seg3@cdc.gov
}

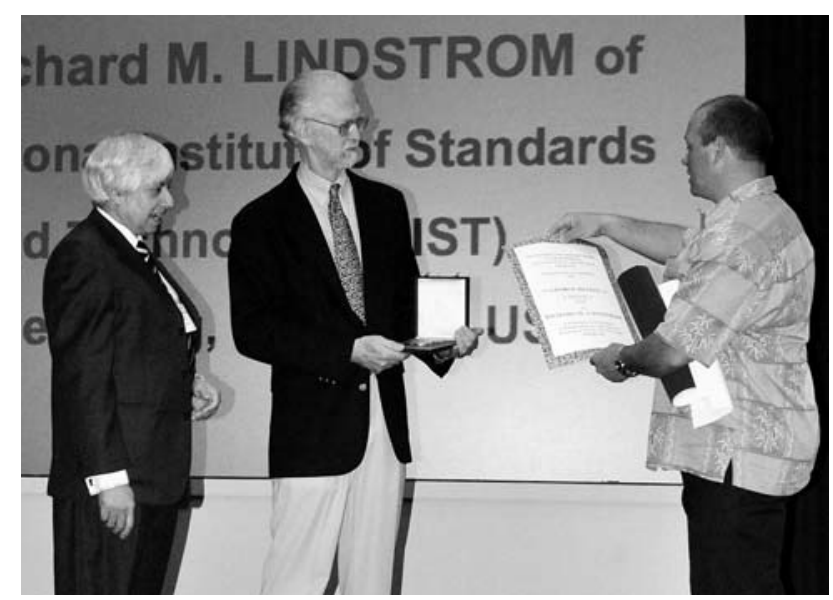

Dr. Lindstrom has contributed significantly to understanding of several fundamental aspects of gamma-ray spectrometry, namely dead time and pileup effects, lossfree counting methods, and methods for determining of peak areas. He developed an interactive computer program called SUM, originally written to address the incorrect calculation of peak area uncertainty in a commercial gamma spectrometry packages, but which also provides improved accuracy in cases where a photopeak is very large, very small, or non-Gaussian.

Dr. Lindstrom has contributed to improved nuclear data, and thus improved accuracy of NAA measurements. He provided a more precise value for half-life of ${ }^{76} \mathrm{As}$ and several other nuclides. As a direct result of his work, the nuclear data evaluation community has changed its algorithms for combining published values. He was one of the first to identify every feature in the background of a gamma-ray detector. He operates a state-of-the-art lowbackground counting facility, and has recently installed a low-background detector more than $500 \mathrm{~m}$ underground. 
Dr. Lindstrom taught courses in PGAA, NAA and metrological issues in expert missions for IAEA in Thailand, Malaysia and Chile. He was involved in supervision of one M.S. and three Ph.D. theses and worked with 23 postdoctoral fellows and visiting scientists, including 6 IAEA fellows. Dr. Lindstrom has published 110 peer-reviewed papers and book chapters, an additional 67 papers in conference proceedings and other reports, and presented more than 120 talks, over 70 of them invited. He has contributed to the certification of 79 NIST Standard Reference Materials.

Dr. Lindstrom has also been active in organizing international and national conferences, and numerous technical sessions at American Nuclear Society national meetings. Most notably, he was organizer and co-chair of the 10th International Conference on Modern Trends in Activation Analysis, Bethesda, 1999. He has been a member of the International Committee on Activation Analysis, chaired the Isotopes and Radiation Division of the American Nuclear Society, served as deputy group leader at NIST from 1995 to 2005, and acted as an adjunct professor at
North Carolina State University. He is a member of several professional societies and has been an Associate Editor of the Journal of Radioanalytical and Nuclear Chemistry since 2007. From 2007 to the present, Dr. Lindstrom has been a NIST Scientist Emeritus, working with postdoctoral fellows, overseeing the design of a new cold-neutron PGAA instrument, establishing an underground low-background counting facility, validating a new delayed-neutron instrument at the NIST reactor, and expanding his external collaborations.

In summary, Dr. Lindstrom's research is multifaceted, with a consistent emphasis on rigorous evaluation of fundamental parameters in support of metrological accuracy and instrument development. In addition to several NIST awards, the United States Department of Commerce has awarded Dr. Lindstrom its second-highest award, the Silver Medal, "for development and delivery of cuttingedge nuclear technology to support U.S. nonproliferation efforts."

It is indeed a pleasure to honor Dr. Richard M. Lindstrom with the Hevesy Medal Award 2009. 